\title{
Supplementary protein and gastro-intestinal parasitism in young grazing sheep
}

\author{
MFJ van Houtert 1,3 , IA Barger ${ }^{1}$, JW Steel 2 \\ ' CSIRO Division of Animal Health, Pastoral Research Laboratory, Armidale 2350; \\ 2 CSIRO Division of Animal Health, McMaster Laboratory, Prospect 2149, Australia ; \\ 3Present address: Animal \& Veterinary Sciences Group, Lincoln University, Canterbury, New Zealand
}

Nutritional status of ruminants influences the pathology of gastro-intestinal parasitism. Duodenal infusion with casein alleviated the debilitating effect of Trichostrongylus colubriformis (TRICH) on young sheep, in contrast to infusion with glucose (Bown et al, 1991, Aust J Agric Res, 42, 253-267). Van Houtert et al (1994, Vet Parasitol, in press) successfully used fish meal to alleviate the effects of TRICH on productivity of young Merino sheep fed hay. Fish meal also enhanced the rate of expulsion of $\mathrm{TRICH}_{\mathrm{B}}$. Much less is known about the influence of protein nutrition on the impact of nematode infections in young grazing sheep. The present study assessed the effects of protein supplementation on production responses in young grazing sheep and on parasite population dynamics and development of host immunity.

Young Merino wethers $(n=270)$ grazed 27 experimental paddocks ( 10 animals per 0.8 ha paddock initially). Three supplementation (Su) treatments and 3 regimes of nematode control (drench ; DR) were assigned in a factorial fashion and each replicated 3 times. Sheep were given no supplement (Su0) or pelleted supplements $(200 \mathrm{~g} / \mathrm{d}$ fed three times a week) containing $25 \%$ lucerne meal and either $75 \%$ sunflower meal (Su1) or $75 \%$ formaldehyde-treated sunflower meal (Su2). Nematode control consisted of : no drenching other than to avoid death (Dr0), strategic drenching programme (DR1) or controlled-release albendazole capsule (DR2). Haemonchus contortus was excluded through use of a narrow-spectrum anthelmintic.
Drought conditions required feeding of lucerne hay to all sheep from week 14 till the end of the experiment at week $36(350 \mathrm{~g} / \mathrm{head} / \mathrm{day}$ fed twice a week). Two sheep per paddock (6 per treatment) were slaughtered after 16 or 27 weeks for worm burden. Paddocks were the experimental unit for statistical analysis.

Live-weight gain (LWG) was increased by supplementation from $40 \mathrm{~g} / \mathrm{d}$ (Su0) to 64 and $67 \mathrm{~g} / \mathrm{d}$ (Su1 or Su2 ; $P<0.001$ ). Anthelmintic treatment increased LWG from 52 (DR0) to 59 or $61 \mathrm{~g} / \mathrm{d}$ (DR1 or DR2 ; P<0.001). Undrenched animals given Su1 or Su2 tended to grow faster (mean $61 \mathrm{~g} / \mathrm{d}$ ) than unsupplemented animals in the Dr1 and DR2 groups (mean 44 $\mathrm{g} / \mathrm{d}$ ). Greasy wool production was increased by supplementation $(6.2,9.3$ and $9.6 \mathrm{~g} / \mathrm{d}$ for SuO, Su1 and Su2; $P<0.001)$ and by anthelmintic treatment $(7.5,8.7$ and $8.9 \mathrm{~g} / \mathrm{d}$ for DR0, DR1 and Dr2; $P<0.001)$. In undrenched sheep mean faecal worm egg counts (FEC) over the 36 weeks were lower for Su1 and Su2 sheep (mean 425 eggs per gram (EPG)) than for Su0 sheep (mean 910 EPG ; $P<0.05$ ). Supplementation had no effects on FEC in DR1 or Dr2 sheep (mean FEC 210 EPG). Worm burden was generally unaffected by supplementation. The predominant nematode species was TRICH, with small numbers of other species also present.

Supplementary feeding with protein meal substantially reduced production losses associated with nematode infection in young grazing sheep. Supplementation appeared to have little impact on the rate of development of protective immunity. 